\title{
Monitoring Vegetation Change in the Dryland Ecosystem of Sokoto, North- western Nigeria using Geoinformatics
}

\author{
Abubakar Magaji Jibrillah ${ }^{1,2}$, Mokhtar Ja'afar ${ }^{1}$ and Lam Kuok Choy ${ }^{1}$ \\ ${ }^{1}$ Social, Environmental and Developmental Sustainability (SEEDS). Research Centre Faculty of Social Sciences \\ and Humanities, Universiti Kebangsaan Malaysia. \\ ${ }^{2}$ Department of Geography, Usmanu Danfodiyo University, Sokoto, Nigeria.
}

Received: 2018-02-12

Accepted: 2019-01-03

Keywords:

vegetation;

change;

dryland;

ecosystem;

geoinformatics.

Corespondent Email:

ajibrillah@gmail.com

\begin{abstract}
The dryland ecosystem of Sokoto state, in the North-western part of Nigeria has been witnessing gradual loss of vegetation cover in the recent decades caused by natural and human induced drivers of ecosystem change. This negative trend poses great challenges to both the physical environment and the people of the area, particularly due to the fragile nature of the ecosystems in the region and the peoples' over dependence on it for their livelihoods. This study tries to monitor and assess the rate of change in the spatial distribution of vegetation in the area over the time and identify the drivers responsible for changing the vegetation. This is with a view to providing evidence-based information to the policy makers that would guide them in making informed decisions that would assist in conserving the vegetation and the entire ecosystem of the area. Using multi-temporal MODIS-NDVI satellite data, image processing and GIS techniques, this research work tries to monitor and assess gradual change in vegetation cover in Sokoto state, North-western Nigeria. Correlation analysis was also used to measure the degree of relationship between vegetation change and some drivers of ecosystem change in the area. The findings of the research reveal a gradual but persistent decline in vegetation cover in the area, both during the rainy and dry seasons. This is also show a strong positive relationship with the rainfall distribution and a perfect negative relationship with the population distribution of the area. This indicate that, both climate change and anthropogenic drivers plays a significant role in changing vegetation distribution of the area. Anthropogenic drivers however, play a more significant influence. The degree of relationship is however, stronger during the dry season, making the ecosystem more vulnerable during the dry season due to increasing aridity. Although change in the vegetation cover of the area seems to be gradual and unnoticed, if left unchecked the long-term cumulative impacts could have serious negative impacts on both the structure and functions of the ecosystems of the area. This could in turn, affect the livelihoods and socio-economic development of the area.
\end{abstract}

\section{Introduction}

The role of vegetation cover in stabilising global ecosystem cannot be overemphasized. This is because, vegetation provides the base and support to all life forms through its role of primary production and plays a vital role in the global climate system. Specifically, vegetation provides food, shelter and raw materials to man, pasture to livestock, protects soil from erosion and provides fuel woods amongst other things to the inhabitants of the semi-arid environment of Sokoto (Adegboyega et al, 2016; Zhigila et al, 2015). Periodic assessment of vegetation condition is therefore necessary for understanding the effects of different drivers of change on spatio-temporal distribution of vegetation. This is particularly important in the dryland environment of Sokoto due to the fragile nature of the ecosystem in the region and the peoples' over dependence on it for their livelihoods. However, over the last decades, vegetation of the area has been experiencing major disturbances mainly due to human activities coupled with other natural processes with serious consequences on the natural vegetation, biodiversity, food security as well as socio-economic development of the area (Marian et al' 2014).

Urban and agricultural expansions caused by the rapid population growth in the area, are among the major drivers of vegetation change in the area (Pooter et al, 2004). Other sources of vegetation disturbances in the area includes, overgrazing, fuel wood extraction, bush burning and desert encroachment all of which poses serious ecological, social and economic consequences (Mohammed, 2015; Olagunju 2015). Climate change and associated challenges further aggravates these challenges (Intergovernmental Panel on Climate Change (IPCC), 2013; Millennium Ecosystem Assessment (MEA), 2005). This underscores the need for continuous monitoring and assessment of the spatio-temporal changes in the vegetation of the area, as well as understanding the influence of different 
drivers of ecosystem change in altering the vegetation distribution of the area. This type of information is necessary to furnish the policy makers with evidencebased information necessary for ensuring informed decision that could lead to proper resource utilisation and sustainable development of the area. This to a very large extent will depend on our ability to monitor and assess the spatio-temporal state of vegetation and impacts of global environmental changes on different components of the ecosystem. This may prove difficult with the conventional ground survey techniques as they cannot keep face with the rate of changes and particularly over large areas. Also, the fact that, vegetation disturbances and changes do not occur in a linear and easily recognizable pattern compounds the problem. Combinations of GIS and remote sensing techniques will no doubt yield a positive result in this regard. This particularly in view of the fact that, during the last few decades, remote sensing satellites provided global monitoring necessary for improving our understanding of the ecosystem dynamics. Multitemporal satellite images such as Landsat data, Advanced Very High Resolution Radiometer (AVHRR) and Moderate Resolution Imaging Spectrometer (MODIS) of the same area can be used to study the susceptibility of land and changes resulting from both natural and anthropogenic drivers. (United Nations Geological Survey (USGS), 1997; Kumar et al., 2010). In addition, GIS has the ability to combine and integrate data from varied sources such as from cartographic sources (maps), earth bound surveys, remote sensing (aerial and satellite imageries) and create overlapping layers that can be accessed, transformed and manipulated interactively in one spatial structure (Kaminska et al,

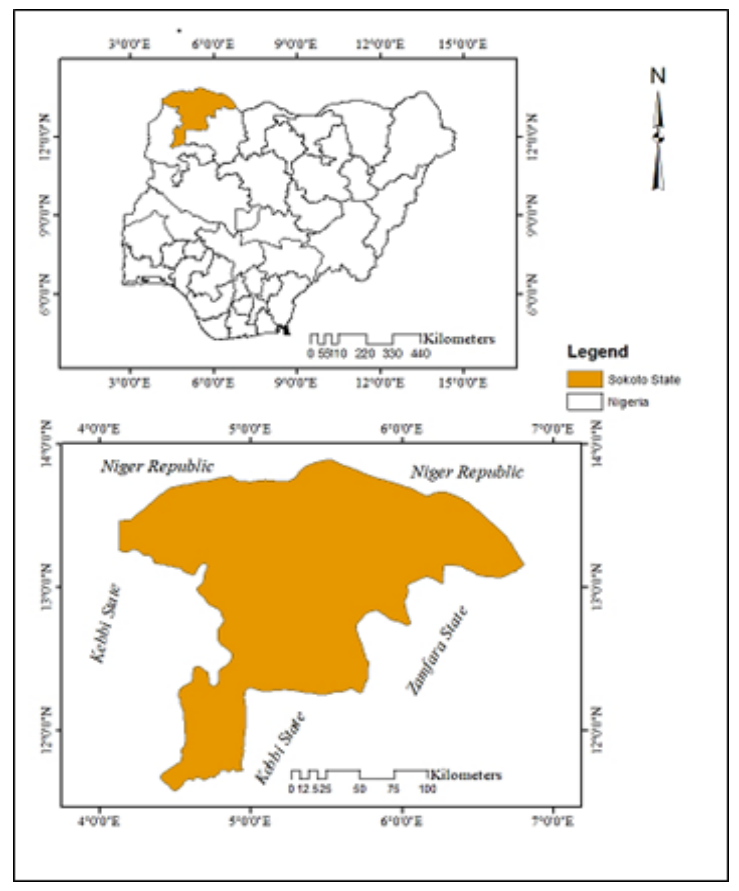

Figure 1. The Study Area.
2004). It is against this background that, this research utilises multi-temporal MODIS-NDVI satellite data to monitor and assess vegetation changes in the dryland ecosystem of Sokoto, North-western Nigeria. Remote sensing data has been extensively used in vegetation and ecosystem studies in different parts of the world (Elmore et al, 2000; Kumar et al, 2010; Al-Rawashdeh, 2012; Usman, et al, 2012; Aliyu, 2013 and Mirzaei et al, 2015).

Sokoto State is situated in the North-western part of Nigeria. It is located between latitudes $11^{\circ} 30^{\prime \prime}$ to $13^{\circ} 50^{\prime \prime}$ $\mathrm{N}$ and longitudes $4^{\circ} 00^{\prime \prime}$ to $6^{\circ} 00^{\prime \prime} \mathrm{E}$ (See Figure 1 ). The state shares common boundaries with the republic of Niger to the North and West, Zamfara State to the East and Kebbi State to the South. The area is characterized by tropical continental climate with a very fragile ecosystem. Temperatures are high throughout the year while rainfall, low and erratic which barely lasts for more than five months in a year. Average annual rainfall barely exceeds $629 \mathrm{~mm}$ while temperatures could be as high as $39^{\circ} \mathrm{C}$ or even higher, particularly during the month of April which usually records the highest of temperature. The area is also characterized by Sudan Savannah type of vegetation dominated by short grasses interspaced by short woody trees and shrubs. Grasses looks green during the rainy season, but eventually withered and die during the dry season (Davis, 1982).

\section{Methods}

The research was based essentially on the analysis of multi-temporal remote sensing satellite data. The basic data for this research is MODIS-NDVI (MOD13Q1), obtained from the Moderate-resolution Imaging Spectroradiometer (MODIS), onboard NASA's Terra (EOS AM) and Aqua (EOS PM) satellite that combines the characteristics of AVHRR and Landsat sensors to provide improved monitoring of the earth's surface at global scale. MODIS Normalised Difference Vegetation Index (NDVI) as one of the products of the of MODIS is designed to provide consistent spatial and temporal comparisons of vegetation condition using blue, red and near-infrared reflectance centred at 469 nanometres, 645 nanometres and 858 nanometres respectively (Didan, 2015). The data is computed from the atmospherically corrected bi-directional surface reflectance that have been masked for water, clouds, heavy aerosols and cloud shadows. MOD13Q1 data are provided every 16 days at 250 meters spatial resolution and is widely used for global monitoring of vegetation conditions and land cover changes. NDVI has been widely used to study changes in the spatial pattern of vegetation (Chen et al. 2014; Jackson et al., 2004; Matson \& Bart, 2013; Olexa \& Lawrence, 2014; Vogelmann et al. 2012; Zhao et al. 2014; Zhou et al. 2015).

NDVI is derived from the ratio of red and near infrared reflectance and is based theoretically on the fact that, vegetation chlorophyll absorbs red rays of the electromagnetic spectrum (EMS), while mesophyll leaf 


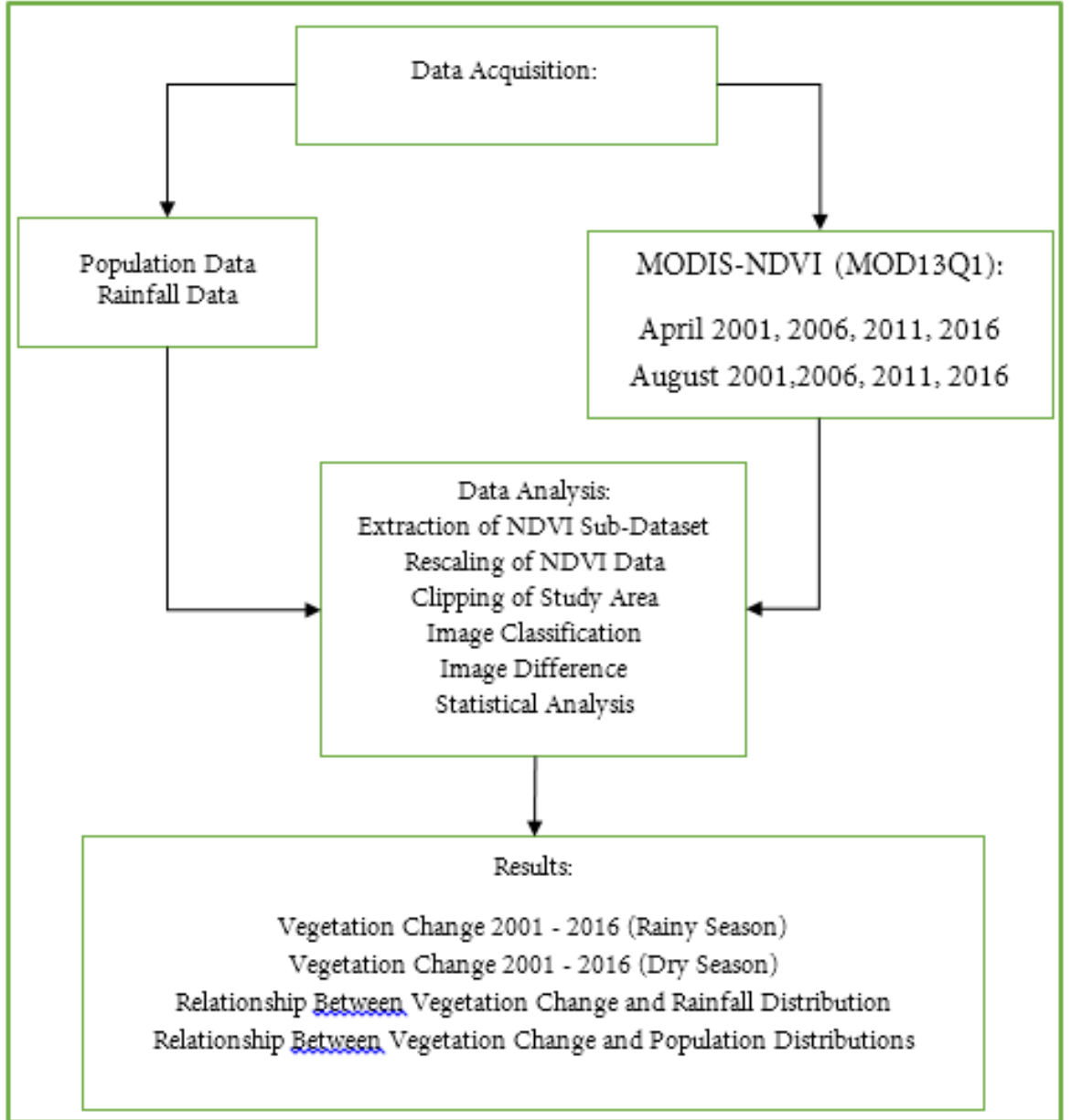

Figure 2. Flowchart of the Research Methodology

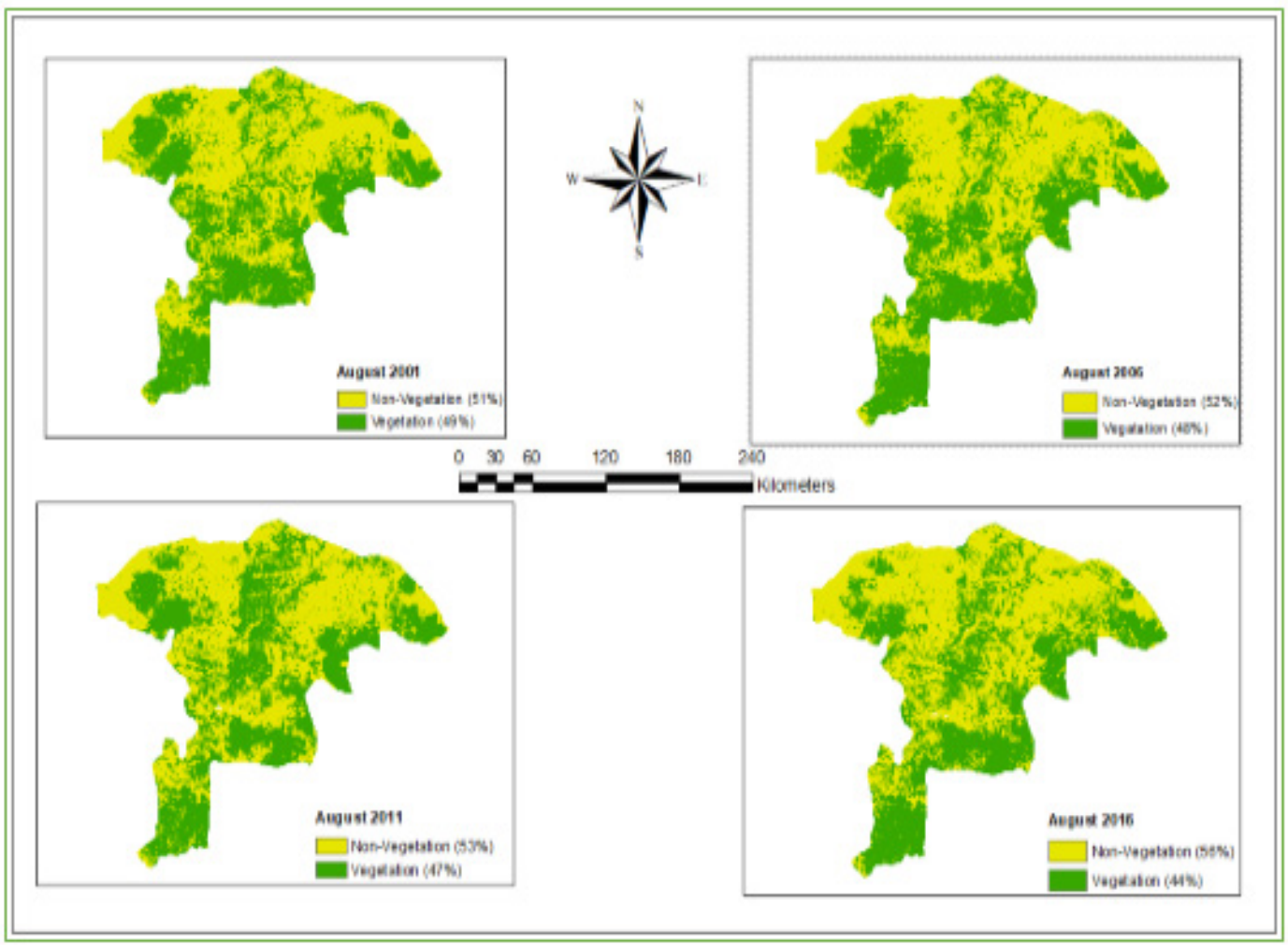

Figure 3. Vegetation Cover during the Rainy Season 


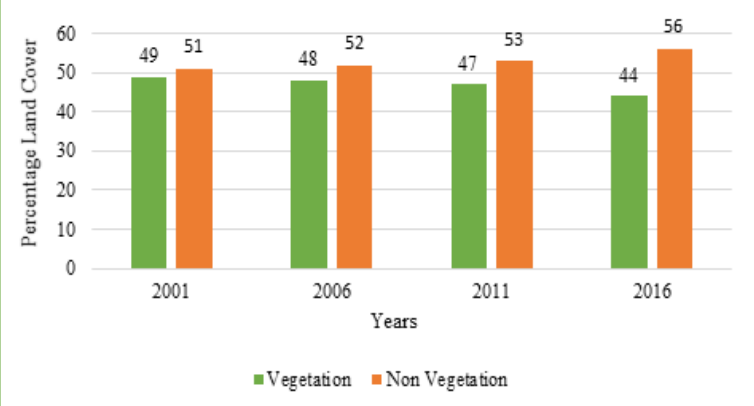

Figure 4. Relative Percentage of Vegetation Cove during the Rainy Season

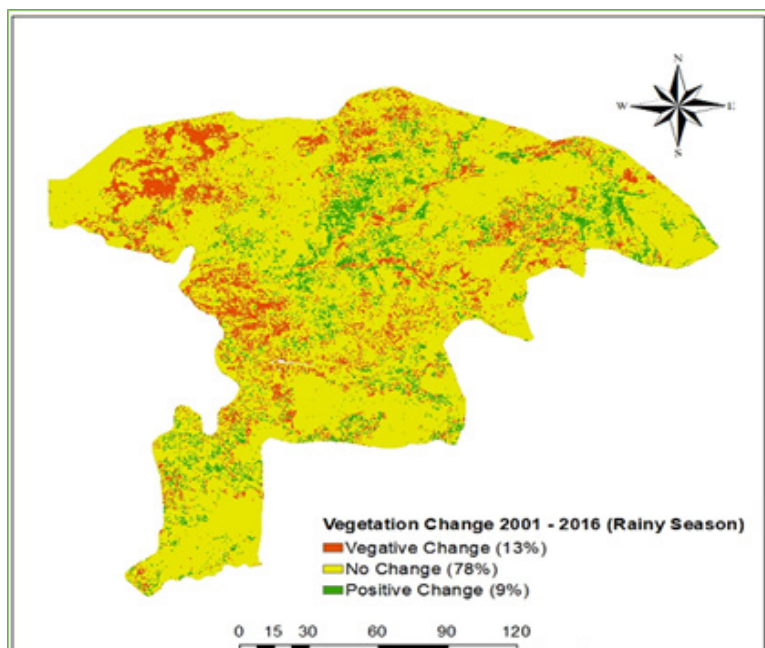

Figure 5. Vegetation Change from 2001 - 2016 during Rainy Season

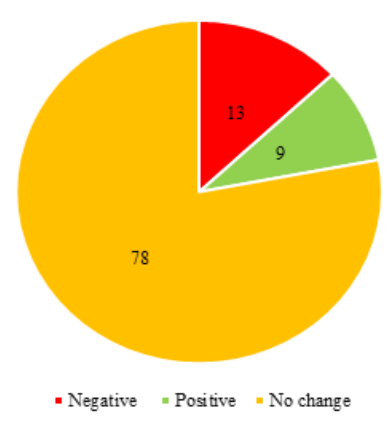

Figure 6. Relative Percentage of Rainy Season Vegetation Change 2001 - 2016

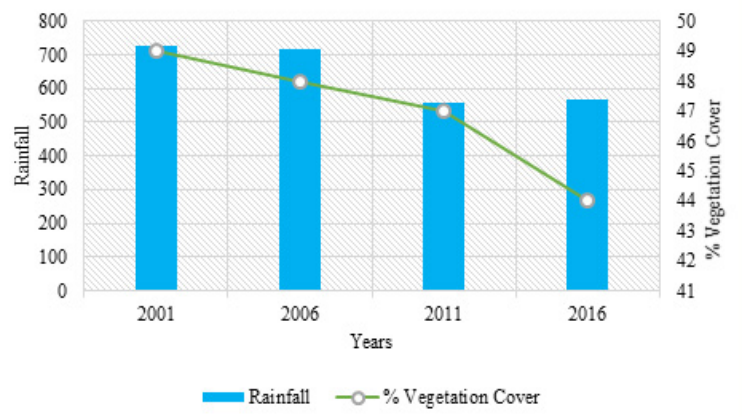

Figure 7. Relationship between Rainfall Distribution and Percentage Vegetation Cover in Rainy Season

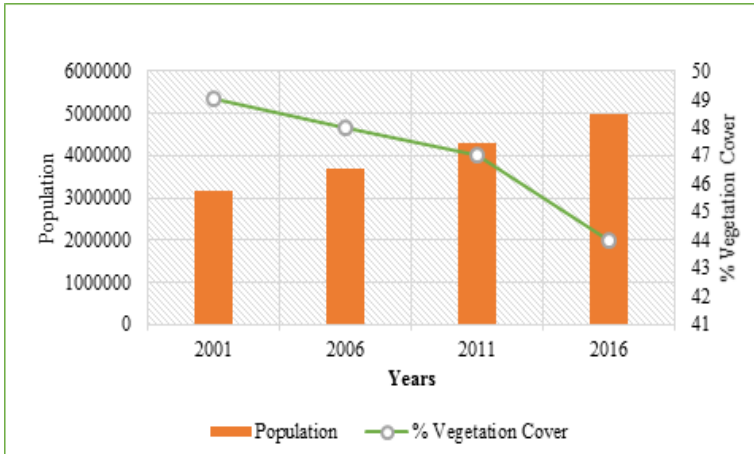

Figure 8. Relationship between Population Distribution and Percentage Vegetation Cover in Rainy Season

structure scatters near infrared rays of EMS, leading to low reflectance in red and high reflectance in the near infrared regions of the EMS, the ratio of which is used to discriminate vegetation from other types of land cover. Theoretically, NDVI values are represented as a ratio ranging from -1 to +1 , but in practice, values from 0 to -1 represents different types of non-vegetation land cover surfaces such as water (extreme negative values), built up areas and bare soil, while values from 0.1 to 1 , represents different shades of vegetation cover (Borelli et al., 2014; Cao et al. 2010; Li et al. 2014; Pettorelli et al., 2014; Rose et al. 2015; Shalaby \& Tateish, 2007; Tunner et al., 2003; Vogelmann et al. 2012; Zhou et al. 2015).

To monitor the changes in the spatial distributions of vegetation in the study areas, MOD13Q1 for the month of August (29th August) 2001, 2006, 2011 and 2016 were obtained and analysed to monitor the vegetation change during the rainy season. The same images were also obtained for 7 th April of the same years and analysed to monitor the condition and changes in vegetation distributions during the dry season. The original MOD13Q1 was subjected to a series of processing techniques using ArcGIS 10.3 software. Theses includes extraction of NDVI sub-dataset from a series of data-sets contained in "MOD13Q1" vegetation indices data, raster calculation to rescale the data range to the original NDVI range of "From -1 to +1 ", re-projection of the original dataset from sinusoidal projection to WGS 84, for appropriate representation of the study area, clipping of the study area from the larger dataset.

To distinguished vegetation from non-vegetated surfaces, the original NDVI images were reclassified by assigning the values from -1 to 0 to represent nonvegetation areas while values from 0.1 to 1 represents vegetation areas. A simple image differencing was then applied to measure the amount of vegetation change between 2001 to 2016. The result was evaluated and validated via ground truthing during which coordinates of different land cover classes was captured using GPS receiver. The Coordinates were used as ground control points (GCP) to verify the locations of different land cover classes on the images and 


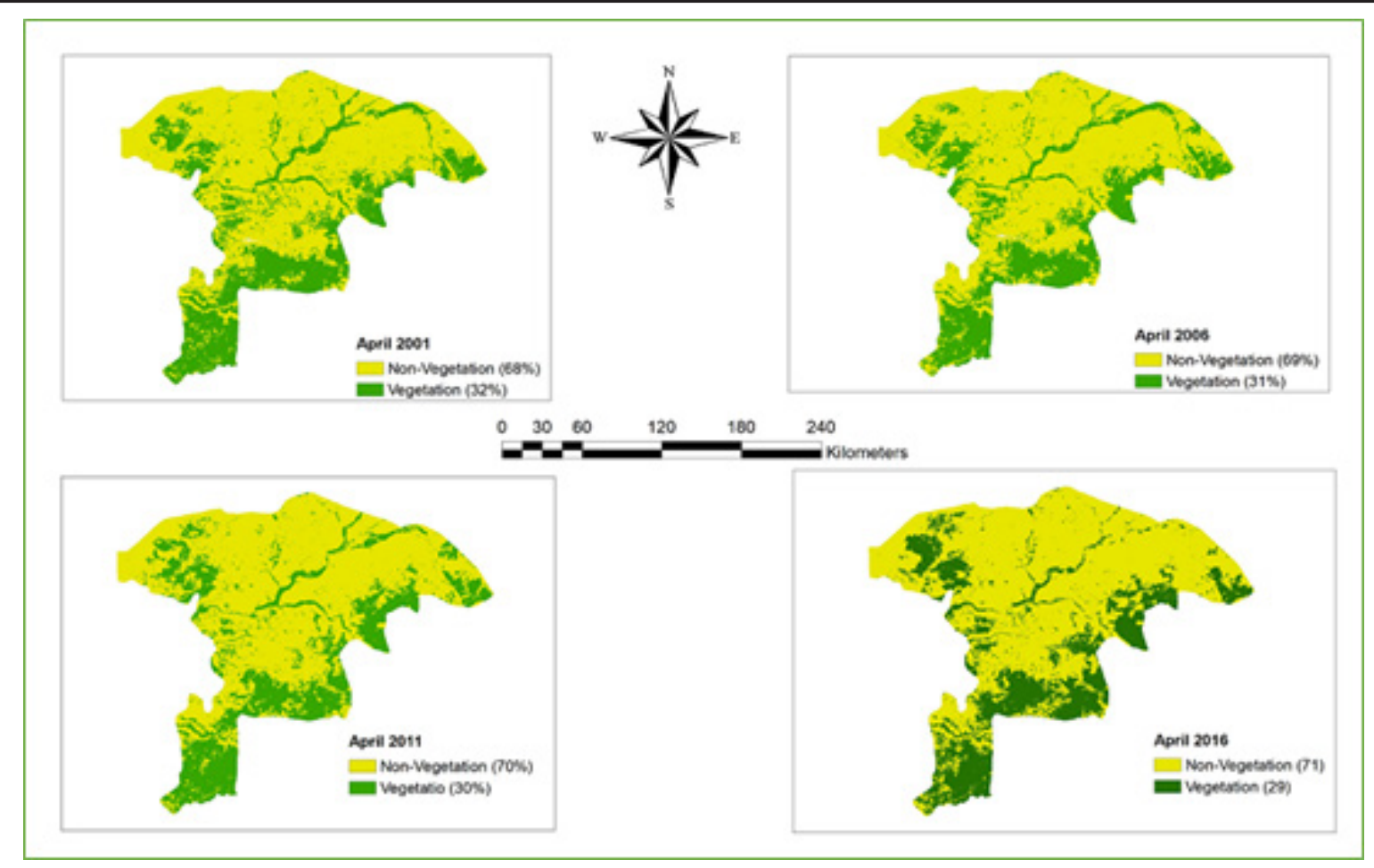

Figure 9. Vegetation Cover during the Dry Season

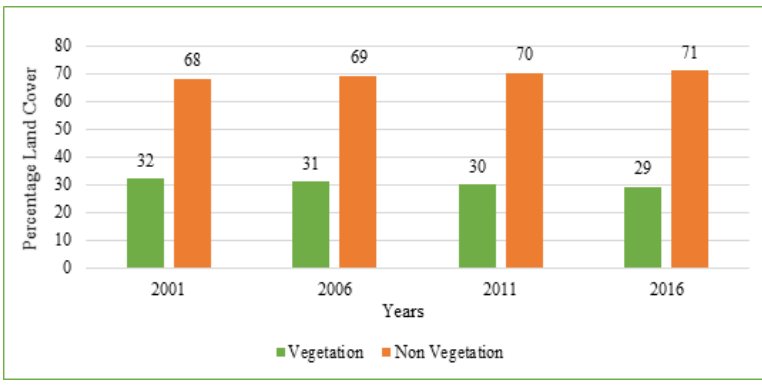

Figure 10. Relative Percentage of Vegetation Cove during the Dry Season

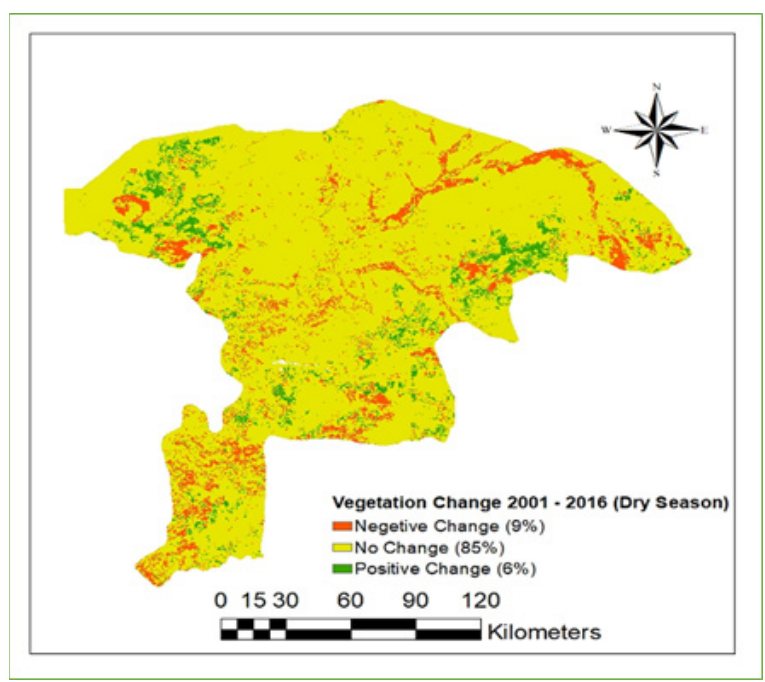

Figure 11. Vegetation Change from 2001 - 2016 during Dry Season

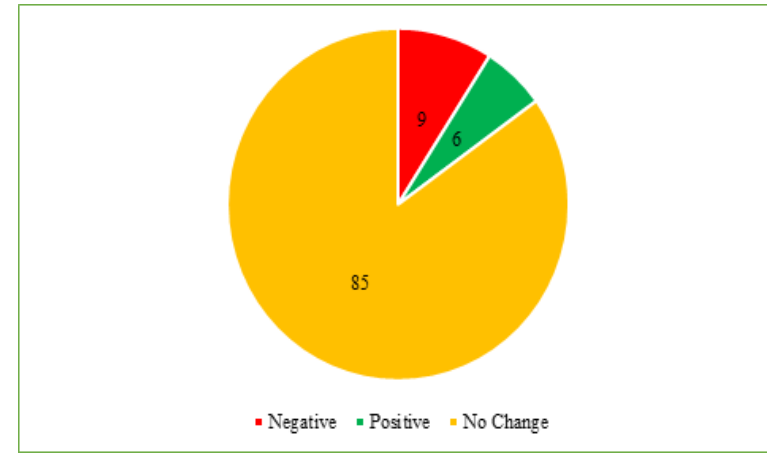

Figure 12. Relative Percentage of Dry Season Vegetation Change 2001 - 2016

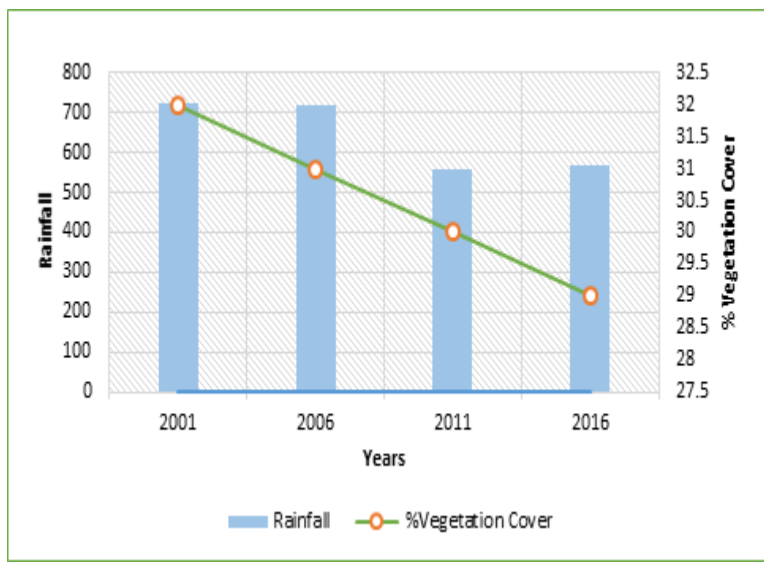

Figure 13. Relationship between Rainfall Distribution and Percentage Vegetation Cover in Dry Season 


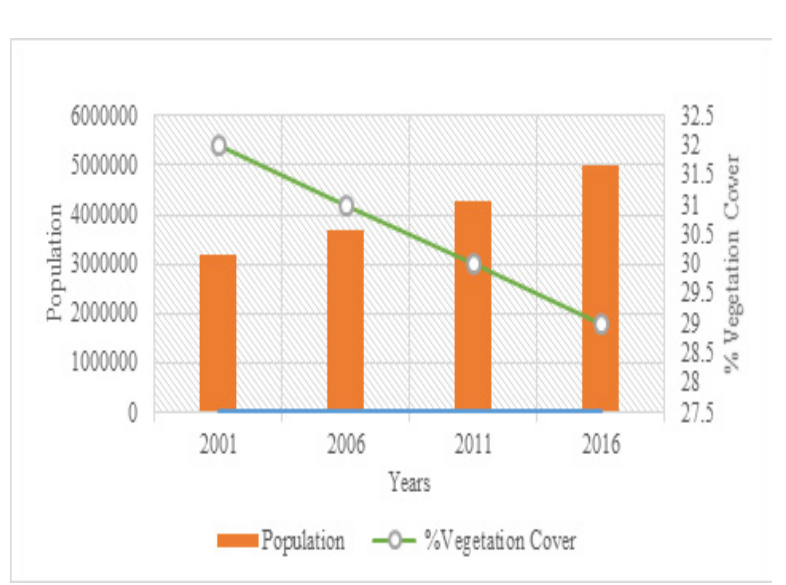

Figure 14. Relationship between Population Distribution and Percentage Vegetation Cover in Dry Season

compare what was obtained on the ground with what was on the image. Using this method, an accuracy of over $93 \%$ was obtained. The result was then correlated with the rainfall distributions of the study area obtained from the Nigeria Meteorological Agency (NIMET), to ascertain the influence of climate change, and with population distribution of the area obtained from the National Population Commission (NPC), to ascertain the influence of population growth on vegetation change. Figure 2 below summarized the procedures involved in the research methodology.

\section{Results and Discussions}

The result of this research reveals a gradual but persistent decline in vegetation cover in Sokoto state both during the rainy season and in the dry season. Figure 3 reveals the condition of vegetation cover during the month of August in the years 2001, 2006, 2011 and 2016. This period is the peak of the rainy season in the area when the vegetation cover attains its highest level in terms of growth, density and spatial distributions.

From the figure 3, vegetation during the rainy season covers $49 \%$ of the total land area of the state in 2001. This reduced to $48 \%$ in $2006,47 \%$ in 2011 and $44 \%$ in 2016 . Figure 4 , show graphical representation of the relative percentage of vegetation and non-vegetation cover of the study area during the years under review.

Figure 4 revealed a gradual but persistent loss of vegetation cover in the area. This type change is gradual and often unnoticed, but its cumulative impact over a long period could have very serious negative impacts on the entire ecosystem of the area. This type of change can over the time alter both the structure and function of the entire ecosystem including the supply of the ecosystem goods and services. This could in turn, affects the livelihoods of the people due to their heavy dependence on the ecosystem for livelihood. Figures 5 and 6 shows the amount of vegetation change in the area from 2001 to 2016.
Figures 5 and 6 shows the relative percentage of vegetation change in the state, from 2001 to 2016. Based on the figures, $13 \%$ of the total land area in the state recorded negative change or decrease in vegetation cover, $9 \%$ recorded positive change or increase in vegetation cover and these are usually areas where plantation agriculture or government afforestation programmes are established. Also, 78\% of the total land area recorded no change in the vegetation cover. Many drivers of ecosystem change both direct and indirect, as well as natural and anthropogenic drivers could be responsible for these changes. Some of these drivers of change that operate at different degrees in the study area includes climate change, rapid population growth, urban expansions, land use conversions, over cultivation, over grazing, deforestation as well as desertification and desert encroachment among others (Eniolorunda \& Bello, 2011; IPCC, 2013; MA, 2005; Mohammed, 2015; Olagunju, 2015). The cumulative impacts of all these has been a gradual loss of vegetation cover in the area with serious ecological and socioeconomic consequences.

To measure the influence of some of the drivers of change in changing the vegetation of the area however, the above result was correlated with rainfall and population distributions of the study area over the same years (Figures 7 and 8). The result shows the existence of a strong relationships with two drivers of change in the study area. A strong positive relationship exists between annual rainfall distribution and percentage vegetation cover in the area with the correlation coefficient of 0.77 , while a near perfect negative relationship exist between population distribution and percentage vegetation cover with the correlation coefficient of -0.97 . This indicate that, both climate change and population growth significantly influences the spatial distribution of vegetation in the study area.

Based on figure 7 , both rainfall distribution and vegetation cover are declining. This confirm the negative influence of climate change and variability on vegetation distributions and the entire ecosystem of the area. Dryland ecosystems world over, part of which is the study area, has over the recent decades experienced a decline in the amount and duration of rainfall as one of the symptoms of recent climate change (IPCC, 2013). This is one of the principal causes of decline in vegetation cover of the area. This can significantly affect both the structure and functions of the ecosystem of the area.

Figure 8. revealed an inverse relationship between population growth and spatial distribution of vegetation in the study area. This confirmed the negative impacts and populations growth and associated drivers of change in reducing the vegetation cover of the area which could in turn affects the structure and function of the entire ecosystem. This is particularly in view of the important roles of vegetation in the ecosystem. In particular, population growth lead to increase in the demand for 
ecosystem goods and services including food, shelter, gazing areas, water, and other urban infrastructural facilities. This in turn, lead to massive resource exploitation, unsustainable land management practices and land use conversions to meets these demands, leading to decline in vegetation cover of the area. Some of these includes overcultivation, overgrazing, bush burning, deforestation and urban expansion, which in themselves results in the loss of vegetation cover and also contributes significantly to the processes of climate change with its associated consequences on vegetation and ecosystem at large.

Similar declining trend in the spatial distribution of vegetation cover as observed in the rainy season, was also observed during the dry season. Figures 9 and 10 shows the situation of vegetation in the April, which is the peak of the rainy season in the study area. During this period, the vegetation cover in the state grossly reduced in terms of growth, spatial distribution and density. This because, the long period of dryness has resulted in the drying and eventual death of annual herbaceous grasses, leaving only stunted shrubs, interspaced by short woody tress. Also, during this period, the rainfed cultivated areas are devoid of vegetation as all rainfed crops are harvested, which also reduced to a large extent the vegetation cover of the area.

Based on figures 9 and 10, dry season vegetation in the state covers $32 \%$ of the land area in 2001 . This gradually decreases to $31 \%$ in 2006, 30\% in 2011 and $29 \%$ in 2016. Again, this change looks very subtle, gradual and often unnoticed, but if left unchecked, the cumulative long-term impacts could be very devastating to the ecosystem and its ability to provide essential goods and services necessary for livelihoods and socio-economic development of the area. Figures 11 and 12 shows the rate of vegetation change from 2001 to 2016 during the dry season.

Based on the Figures 11 and 12 above, 9\% of the total land area, recorded negative changes or decrease in vegetation cover, $6 \%$ recorded positive change or increase in vegetation cover, while $85 \%$ of the total land area in the state did not record any change in the vegetation cover. Causes and impacts of these changes are the same as in the rainy season but the severity of the causes and impacts are higher during the dry season due to the increasing dryness, higher temperatures and moisture scarcity during the time as confirmed by the correlations between dryland vegetation distribution, rainfall distribution and population distributions as shown by figures 13 and 14 .

Figure 13, show a stronger positive relationship between rainfall distribution and vegetation distribution during the dry season as compared to the situation in the rainy with a correlation coefficient of 0.88 . This suggest a stronger influence of climate change and variability on vegetation and ecosystem during the dry season than rainy season in the area.
Figure 14. revealed a more perfect negative relationship between population growth and vegetation distribution in the dry season as compared to the situation in the rainy season. This suggest a stronger impact of anthropogenic drivers of ecosystem change in the dry season.

The observed changes in the vegetation distribution can have serious negative consequences to both the environment and the inhabitants of the area. This is because declining vegetation cover can lead to increased soil erosion and land degradations through the action of wind and running water, which could in turn, lead to loss of agricultural and grazing lands, reduced the agricultural output of the area, increased food shortage, hunger, poverty and diseases. It can also worsen the desertification and desert encroachment that is already a serious threat in the area. Other negative effects could include depletion of water resources, reduced biodiversity and alteration of ecosystem which could negatively affects the supply of ecosystem goods and services in the area. This can also result in serious conflict over land its resources and eventual forced migration of some communities.

\section{Conclusion}

The finding of this research clearly showed a declining trend of vegetation cover in the dryland areas of Sokoto, in the North-western part of Nigeria. This is a very dangerous development particularly due to the already fragile nature of the ecosystems in the area and the over dependence of the people of the area on it for their livelihood. Vegetation being the primary producer upon which all other components of the ecosystem depends therefore need to be preserved and used sustainably if any meaningful development is to be achieved. Some of the major drivers of this changes as mentioned earlier includes climate change and variability, over cultivation, over grazing, bush burning, fuel wood extraction, urbanisation and other unsustainable land management practices (Olagunju, 2015; Mohammed, 2015). The immediate effects of these changes that manifested in the area includes reduction in the natural productivity and potentials of land, loss of agricultural and grazing land, depletion of surface and sub-surface water, alteration of ecosystems, conflicts over land and its resources, increasing poverty and migration. To avert this ugly situation therefore requires a concerted effort from the government, individuals and all stake holders though such measures as public awareness, protection of marginal lands, sustainable farming and land management practices, afforestation, provision of alternative sources of energy and the use of alternative means of livelihoods with minimal negative impacts on the ecosystem of the area. 


\section{References}

Adegboyega, S. A., Olajuyigbe, A. E., Balogun, I. \& Olatoye, O. (2016). Monitoring Drought and Effects on Vegetation in Sokoto State, Nigeria using Statistical and Geospatial Techniques. Ethiopean Journal of Environmental Studies and Management, 9(1), $56-69$.

Aliyu, M. M. (2013). Assessment of Lost of Agricultural Farmlands Using Remote Sensing Techniques in Gudu Local Government Area of Sokoto State, Nigeria. Journal of Educational and Social Research, 3(8), 145 -150.

Al-Rawashdeh, S. B. (2012). Assessment of Change Detection Methods based on Normalised Difference Vegetation Index in Environmental Studies. International Journal of applied Sciences and Engineering, 10(2), $89-97$.

Borelli, P., Modugno, M., Panagos, P., Marchetti, M., Schutt, B. \& Montanarella, L. (2014). Detection of harvest forest areas in Italy using Landsat imagery. Applied Geography, 48, $102-111$.

Cao, X., Chen, J., Matsushita, B. \& Imura, H. (2010). Developing a MODIS-based index to discriminate dead fuel from photosynthetic vegetation and soil background in the Asian steppe area. International Journal of Remote Sensing, 31(6), 1589-1604.

Chen, D., Mi, J., Chu, P., Cheng, J., Zhang, L., Pan, Q., Xie, Y. \& Bai, Y. (2014). Patterns and drivers of soil microbial communities along a regional precipitation gradient on the Mongolia plateau. Landscape Ecology, 30(9), 1669 1682.

Davis, G. (1982). Rainfall and Temperature. In Abdu, P. S. 1982. Sokoto State in Maps. An Atlas of physical and Human Resources. Ibadan, University press.

Didan. K. (2015). MOD13Q1 MODIS/Terra Vegetation Indices 16-Day L3 Global 250m SIN Grid V006. NASA EOSDIS Land Processes DAAC. Retrieved from: https://doi.org/10.5067/MODIS/MOD13Q1.006.

Elmore, A. J., Mustard, F., Manning, S. J. \& Lobell, D. B. (2000). Quantifying Vegetation C h a n g e in Semi-arid Environment: Precision and Accuracy of Spectral Mixture Analysis and Normalised Difference Vegetation Index. Remote Sensing of

Environment, 73, 87 - 102.

Eniolorunda, N. B. \& Bello, A. G. (2011). Forest Cover Change Assessment Using Landsat and SPOT Data: A Case Study of Tangaza Forest Reserve, North-west of Sokoto State. Ife Research Publications in Geography, 10(1), 66 - 74.

Intergovernmental Panel on Climate Change (2013). Summary for Policymakers. In T. Stocker, D. Qin, G. Plattner, M. Tignor, S. Allen, J. Boschung, A. Nauels, Y. Xia, V. Bex \& P. Midgley, (eds)., Climate Change 2013: The Physical Science Basis. Contribution of Working Group I to the Fifth Assessment Report of the Intergovernmental Panel on Climate Change. Cambridge University Press, Cambridge, UK and New York, NY, USA

Jackson, T. J., Chen, D., Cosh, M., Li, F., Anderson, M., Walthall, C. \& Doriaswamy, P. et al (2004). Vegetation Water Content Mapping using Landsat Data derived NDWI for Corn and Soya beans. Remote Sensing of Environment, 92, 475 - 482.

Kaminska, I. A., Oldak, A. \& Turski, W. A. (2004). Geographical Information System (GIS) as a Tool for Monitoring and Analysis of Pesticide Pollution and its Impact on Public Health. Annals of Agricultural and Environmental Medicine, 11(2), $181-184$.

Kumar, P., Rani, M., Paudey, P. C., Majumdar, A. \& Nathawat, M. S. (2010). Monitoring of Deforestation and Forest Degradation using Remote Sensing and GIS: A case study of Ranchi in Jharkhand, India. Reports and Opinions, 2(4) $14-20$.

Li, Z., Xu, D. \& Guo, X. (2014). Remote Sensing of Ecosystem Health: Opportunities, Challenges, and Future Perspectives. Sensors, 14(11), 21117-21139. doi:10.3390/s141121117

Millennium Ecosystem Assessment (2005). Ecosystems and human well-being: current state and trends, Volume 1. R. Hassan, R. Scholes, \& N. Ash, (Eds.) Washington DC.

Matson, E. \& Bart, D. (2013). Interactions among fire legacies, grazing and topography predict shrub encroachment in post-agricultural pa'ramo. Landscape Ecology, 28(9), 1829-1840.

Marian, V., Andreas, B., Francois, D., Dario, S. \& Baudouin, D. (2014). Land over Change Monitoring using Landsat MS/TM Satellite Image Data over West Africa between 1975- 1990. Remote Sensing, 6, 658 676.

Mirzaei, J., Mohamadi, A., Heidarizadi, Z., Norolahi, H. \& Omidipour, R. (2015). Assessment of Land Cover Changes using Remote Sensing and GIS (Case Study: Zagros Forests, Iran). Journal of Mater, Environ. Sci, 6(9), $2565-2572$.

Mohammed. N. T. (2015). Desertification in Northern Nigeria: Causes and Implications for National Food Security. Peak Journal of Social Sciences and Humanities, 3(2), 22-31.

Olagunju, T. E. (2015). Drought, Desertification and the Nigerian Environment: A Review. Journal of Ecology and Natural Sciences, 7(7), 196 - 209.

Olexa, E. M. \& Lawrence, R. L. (2014). Performance effects of land cover type on synthetic surface reflective data and NDVI estimate for assessment and monitoring of semi-arid rangeland. International Journal of Applied Earth Observation and Geo-information, $30,30-41$

Pettorelli, N., Laurence, W. F., O’Brien, T. G., Wengmann, M., Nagendra, H. \& Turner, W. (2014). Satellite Remote Sensing for Applied Ecologists: Opportunities and Challenges. Journal of Applied Ecology, 51, 839 848.

Pooter, L., Bonger, F., Kouame, F.T.N. \& Hawthrone, W.D. (2004). Biodiversity of West African Forest - An Ecological Atlas of Woody Plant Species. Oxford, CABI Publishing

Rose, R. a, Byler, D., Eastman, J. R., Fleishman, E., Geller, G., Goetz, S., Guild, L. et al. (2015). Ten ways remote sensing can contribute to conservation. Conservation Biology, 29(2), 350-9. doi:10.1111/cobi.12397

Shalaby, A. \& Tateishi R. (2007). Remote Sensing and GIS for Mapping and Monitoring Land Cover and Land Use Changes in the North-west Coastal one of Egypt. Applied Geography, 27, 28 - 41.

Tunner, W., Spector, S., Gardiner, N., Fladdad, M., Sterling, E. \& Steininger, M. (2003). Remote Sensing for Biodiversity Science and Conservation. Trends in Ecology and Evolution, 18(6), 306-314.

United States Geological Survey (1997). Desertification. Retrieved from: www.pubs.usgs.gov/gip/desert/ desertification/ 
Usman, U., Yelwa, S. A. \& Gulumbe, S. U. (2012). An Assessment of Vegetation Cover across Northern Nigeria using Trend Line and Principal Component Analysis.

Journal of Agriculture and Environmental Science, 1(1), $01-18$.

Vogelmann, J. E., Xia, G., Homer, C. \& Tolk, B. (2012). Monitoring Gradual Ecosystem Change Using Landsat Time Series Analysis: Case Studies in Selected Forest Rangeland Ecosystem. Remote Sensing of Environment, 122, 92 - 105.

Zhao, X., Hu, H., Shen, H., Zhou, D., Zhou, L., Myneni, R. B., \& Fang, J. (2014). Satellite-indicated long-term vegetation changes and drives in the Mongolian Plateau. Landscape Ecology, 30(9), 1599 -1611.

Zhigila, D. A., Sawa, F. B. J., Abdul, S. D., Abba, H. M. and Tela, M. (2015). Diversity and Phytogeographic Investigation into the Woody Plants of West Tangaza Forest Reserve, Sokoto State, Nigeria. International Journal of Plants Research, 5(1), 73 79.

Zhou, D., Zhao X., Hu, H., Shen, H., \& Fang, J. (2015). Longterm vegetation changes in the Four MegaSandy Lands in Inner Mongolia. Landscape Ecology, 30(9), 1613 - 1626. 